\title{
In Conversation with Edward Hare: Part II
}

The following is the second part of Brian Barraclough's interview with Edward Hare. Part I was published last month (Bulletin, February 1985, 9, 22-26).

BMB Let's turn from the Journal to your research. You did some drug trials?

EHH I was concerned to publish articles so as to improve my chances of a consultancy, and the scientific aspect of the controlled trial appealed to me. By modern standards though my studies would seem naive.

BMB Did you discover anything of importance?

EHH Two things-at least they seemed important to me. First, controlled trials clearly showed that sedatives sedate and hypnotics help you sleep. Second, the other drugs I tested showed little or no advantage over a placebo. I concluded, for instance, that antidepressant drugs were effective only by virtue of their sedative effect.

BMB Do you still hold that?

EHH Yes, but I continued to prescribe tricyclic antidepressants because they seemed to have one remarkably useful property. Unlike most sedatives, they didn't cause dependence.

BMB You were involved in a lithium trial?

EHH Yes, with Alec Coppen, Ronnie Maggs and others. I think it was the first test of lithium prophylaxis by a controlled, prospective trial. It was well organized and produced a clear result. But one should always be cautious of accepting positive results from drug trials, because that's the result everyone hopes for.

BMB You had reservations about the findings?

EHH Not really. I was the more ready to accept them because they were the opposite of what I'd expected. I'd thought that in the absence of any sedative effect, the findings would be negative.

BMB Did you have doubts about the long-term value of lithium?

EHH There were a number of reports of damage to the kidney and liver. But there was also the problem of the 'lithium clinic'. Patients attended year after year and often saw a different doctor each time. It became hard to tell if they continued to benefit. And there seemed to me a danger of the patients becoming dependent on the hospital-some patients like having a regular hospital appointment but it's not necessarily to their benefit.

BMB You also looked at reserpine?

EHH Reserpine is interesting because it may have been responsible for the myth (as I take it to be) that antidepressants take a week or two for their effects to begin. When reserpine was introduced for hypertension, its full effect took two or three days to develop. This, I think, led the people who did the first trials of reserpine in anxiety to wait a week or two before assessing the effect, so as to be on the safe side that the drug had had time to act. Now if, in conditions like anxiety or depression, you claim a drug takes some weeks to act, then any natural improvement which occurs during that time can be put down to the drug. The purely sedative action of antidepressants comes on within a few hours, of course.

BMB Did you see any reserpine depressions?

EHH No-I was inclined to think that another myth. People with hypertension may become depressed with or without a drug, and I don't recall any controlled trial being done. Patients receiving a new drug are studied carefully and any untoward change may be put down to it.

BMB You have a reputation as a sceptical physician. Do you think that's the reason you looked into compliance?

EHH Yes. On an occasion when the merits of a drug were being extolled, I said no one could be sure how far patients took the drugs prescribed for them. I was scoffed at, so I thought I'd try to see what really happened. Urine testing seemed a fairly reliable method, and our findings suggested that both for inpatients and out-patients, about $50 \%$ weren't taking their drugs as prescribed.

BMB Do you think concern with compliance is an outcome of having effective drugs?

EHH No. It represents an advance in medical objectivity and a concern with economics - but it also revealed a wise provision of nature: patients don't always take their pills. Doctors tend to over-prescribe, especially in an age of high-pressure salesmanship, and don't always consider the long-term risks.

BMB Shall we turn from drugs to epidemiology? You made a study in Croydon.

EHH Yes, encouraged by Aubrey Lewis who thought epidemiology might yield valuable results for psychiatry. We set out to study what were called 'the new-town blues'. The sociologists believed that poor social facilities were the cause of much neurotic illness in new towns. We compared a population on a new estate in Croydon with one in an old part, using a variety of indices of neurosis. The two groups showed no difference.

BMB Were you pleased with the study?

EHH Many other people made similar studies, and on the whole found the same thing. This suggested an alternative to the sociologists' explanation. It suggested the incidence of neurotic complaints might be much the same in any comparable populations but because new towns were then in the news, the complaints of people who lived there got publicity.

BMB How do you think that fits in with Professor George Brown's view of 'life events' causing mental illness?

EHH My own view is that life events don't cause psychi- 
atric illness, though they may precipitate symptoms in those who Lord Taylor has called the weaker brethren. My guess is that most psychiatric illnesses are due to genetic or physical causes and that much of neurosis and psychopathy is the consequence of constitutional damage in early life-from injury, toxins, infection or poor diet.

BMB You published papers on birth order and birth month?

EHH I liked doing research and writing papers; though not being an academic, I never had any research training. And as I was unlucky - or inept - at getting grants, I had to choose subjects which could be done on a shoestring budget - or on no budget at all. But I was fortunate indeed in my collaborators, among whom were John Price, Eliot Slater and Pat Moran.

In the early 1960s there were three interesting problems about schizophrenia. Was there any association between schizophrenia and birth order, or birth month, or maternal age? Several studies had found schizophrenia commoner among later-born. We repeated these-it was easy to get the facts from the case notes-and found the same thing. But partly perhaps because of the large size of our samples, we were able to suggest that the findings could all be attributed to an artefact. The argument was a bit complex, but I think it is being accepted now.

For birth-month, we were able to get very large samples from the national Mental Health Survey, and confirmed other findings that schizophrenics tended to be born in the winter, and we were also able to show this wasn't so in neurosis and personality disorder. There's no convincing explanation yet, but an environmental cause remains a possibility. When our papers on birth-month first appeared, quite a number of people asked me if I was interested in astrology. Partly in self-defence, I made a study of the history of medical astrology and read a paper on it at the Royal Society of Medicine. I concluded there was a close parallel between astrology and psychoanalysis.

BMB You were the editor of the Statistical Reports of the Bethlem and Maudsley Hospitals.

EHH These reports had been started by C. P. Blacker in 1946. They gave an analysis of in-patient and outpatient numbers by sex, age, diagnosis and so on. One of the conditions of my appointmen to the Maudsley - though not a serious one-was that I should take over the production of these reports. I did so for 15 years and then felt l'd done enough.

BMB Have they been continued?

EHH No-at least not in the same way. The hospital changed so much that our old way of presenting them became out of date.

BMB Do you think they had some value?

EHH There was a belief, after the war, that keeping such statistical registers would be useful both for administrators and researchers. Ours had some value for the hospital when it wasn't changing too fast, and I think they retain some value as historical records. But routine statistics are double-edged. They're easily misconstrued, and a clinician may fear an administrator will use them for his own ends.

BMB You've written papers on unusual subjectsmasturbatory insanity, for example?

EHH I once heard an old charge nurse say of a backward patient that he'd never recover because he masturbated. This struck me as odd and led me to study the literature. The belief that masturbation caused insanity was firmly held during most of the 19th century (it was held by Maudsley, for example)-a classic example of confusing the rules of health with the rules of morality. Immoral behaviour is sometimes a sign of impending illness but rarely a cause.

BMB Did you have many requests for that paper?

EHH Rather few, as I remember. I thought it had fallen on deaf ears - or on covered ears. And I'd had difficulty getting it published. Fleming rejected it and so did the editor of Medical History, but then Slater took it. As I'd had the same difficulty with a paper I wrote on the history of GPI, I turned back to more ordinary subjects.

BMB Talking of memory, I remember your lecture on Faraday's loss of memory.

EHH He was my childhood hero, my ideal of what a scientist ought to be. I liked reading about him, and then came across a manuscript account by his doctor of the short illness he had at the age of 45. It was after that illness that he always complained of a bad memory. I studied the evidence and concluded he'd probably had an ischaemic cerebral attack. But it didn't quite add up-ischaemic attacks don't usually cause an amnesic syndrome-and I don't think I made a real contribution.

BMB Talking of mental problems of the famous, you've written about Virginia Woolf?

EHH Only a review of a book about her.

BMB Did you form an opinion about her mental health?

EHH It seemed clear to me, from Quentin Bell's ${ }^{3}$ excellent biography and from other sources, that she was cyclothymic and suffered attacks of atypical mania and depression. One unusual feature was the physical symptoms she had during her illnesses-palpitations, tremor, pallor. As a child she'd had a severe attack of whooping cough, said to have left her a changed person. That might have been why her psychosis was atypical. But the diagnosis of manicdepression is supported by her family history.

BMB May I turn to an aspect of your own health? You suffer from migraine?

EHH I do.

BMB Others have suffered from it, but you've written about it.

EHH I get a well-developed fortification spectrum but not much headache. It occurred to me to map the spectrum - the semi-circle of lights - on a piece of paper to see how fast it expanded and how long it 
lasted. I did this for a number of attacks, though I had to force myself each time. To my surprise I found the expansion rate was logarithmic and the duration always the same (about 21 minutes). That wasn't what the textbooks said, so I enlisted the help of some 25 volunteers (through the newsletter of the Migraine Society) who agreed to time their own attacks. In those whose spectrum was 'typical' (most were), their observations confirmed my own.

BMB What about sociobiology, a fashionable subject? You reviewed Edward Wilson's book.

EHH A fine book, I thought. He set out to base the study of social behaviour in animals, including man, strictly in terms of biology. That seems to me the only scientific basis there is for sociology, which otherwise becomes a tool of politics or religion.

BMB That leads us on to your remarks about social anxiety, which I found attractive. What did you mean by social anxiety?

EHH It always seemed to me there were two sorts of anxiety-anxiety about one's physical health and anxiety about one's social standing. I was led to write a paper on this (as my contribution to the Festschrift for Eliot Slater) from reading that remarkble book by Keith Thomas, Religion and the Decline of Magic. ${ }^{4}$ It describes how in 17th-century England people resorted to advice from priests and astrologers when they had personal problems or worries, and how in the past 100 years such people have turned increasingly to doctors, especially psychiatrists. But there's no reason to think psychiatrists deal better with such problems than anyone else. I took the view that the best way in which our society could meet this need for counselling would be through a profession of psychotherapy-along the lines of the Foster Report.'

BMB Would you include in this osteopaths, chiropractors, acupuncturists?

EHH Oh no. The aim would be discussion and advice. There are people who have a natural talent for these things. They should be, and would want to be, the members of a psychotherapy profession-which would be quite independent of medicine, though no doubt some psychiatric knowledge would be relevant.

BMB You have a reputation for being properly sceptical. Do you think there are any effective treatments in psychiatry?

EHH Treatment is a difficult word. It covers everything from a quick prescription to years of psychoanalysis. Treatments tend to come and go, and our concern should be to find out if a new treatment is better, quicker or safer than the last one. There are many treatments which temporarily allay the severity of a psychiatric illness, thus helping the patient-or at least those who look after him. I think the real dangers lie in long-term treatment, where unexpected toxic effects may occur. There is a too ready presumption that if a drug helps in the short-run, it will help in the long-run too. In any case, the effect of drugs may be more on the mind than the brain. I remember a medical officer at Springfield who secretly arranged that the nightly sedative should contain no more than a whiff of paraldehyde. All went on normally until the secret leaked out some months later. If one believes, as I do, that psychiatric illnesses have become less severe during the past $\mathbf{4 0}$ years, then the advances in treatment during that time must seem distinctly modest.

But physical treatment forms only a small part of management. The most important part is nursing care. I always thought the patient's relatives were the next most important part. Relatives are a longsuffering lot, too often held to blame. They've put up with a difficult or distressed person before his admission and may well have to do so again after his discharge. If a doctor shows them appropriate sympathy and comfort, this will redound to the patient's benefit.

BMB Would you like to say anything about the future of psychiatry?

EHH For over 60 years psychiatrists have been taught, and have largely believed, the Freudian theory of neurosis. Most of us don't believe it now, but what will replace it? There's no clear line between neurosis and normality, and neurotic symptoms are much influenced by the theories about them. Just after the war, a nation-wide survey of symptoms was made (by Percy Stocks), ${ }^{6}$ and one of the questions was about constipation. A respondent who admitted to constipation was considered to show evidence of neurosis: but we wouldn't say so now. I think the causes of neurosis will be hard to pin down, and will be discovered not by psychodynamics or sociology, but by biological study of what determines a person's constitution.

BMB And the psychoses?

EHH Psychiatry still faces what it's had to face for the past 200 years-the fact that nothing useful is known about what causes the common serious illnesses we now call schizophrenia and affective psychosis. We don't know how to prevent them and treatment is still largely palliative. The discovery of their causes remains the principal goal of psychiatric research.

REFERENCES

'DDEGARD, O. (1967) Changes in the prognosis of functional psychosis since the days of Kraepelin. British Journal of Psychiatry. 113, 818-22.

2Bleuler, M. (1978) The Schizophrenic Disorders. (Translated from the German (1972) by S. M. Clemens.) Yale University Press.

${ }^{3}$ Beu, Q. (1972) Virginia Wool: A Biography. London: Hogarth Press.

"ThomAs, K. (1971) Religion and the Decline of Magic. London: Weidenfeld and Nicholson.

'FosTer, J. G. (1971) Enquiry into the Practice and Effects of Scientology. London: HMSO.

'Stocks, P. (1949) Sickness in the Population of England and Wales, 1944-47. London: HMSO. 